\title{
From seafloor geomorphology to predictive habitat mapping: progress in applications of biophysical data to ocean management.
}

\author{
Peter T. Harris \\ Senior Marine Science Advisor, Geoscience Australia \\ GPO Box 378 Canberra ACT 2601, Australia
}

Topic H: geophysics of the marine environment

\begin{abstract}
Hydrographic surveys are carried out mainly to ensure safe navigation, but there are other reasons for mapping the seafloor. These include: (1) to support government spatial marine planning, management, and decision making; (2) to support and underpin the design of marine-protected areas (MPAs) and fishing reserves; (3) to conduct scientific research programs aimed at generating knowledge of benthic ecosystems and seafloor geology; (4) to conduct living and nonliving seabed resource assessments for economic and management purposes; and (5) to support the construction of ports and offshore structures (oil and gas production facilities, wind farms, etc.). The geomorphology of the seafloor, interpreted from bathymetric data combined with geological knowledge, can provide a basic level of information to support goals such as these. By combining multiple spatial biophysical data layers (eg. depth, slope, rugosity, water temperature, primary production, etc.) using multivariate statistical techniques, scientists have produced integrated "seascape" maps to further assist ocean managers. Adding direct observations of marine life to seascapes provides the basis for generating predictive habitat maps, derived using statistical methods (maximum entropy or decision-tree techniques), which depict the potential distribution of species and benthic communities and that are useful for decisionmaking regarding conservation and management. These three broad categories of spatial seafloor classification (geomorphology, seascapes, and predictive habitats) also represent a progression for the utilization of environmental information, from datapoor to data-rich situations. Here we review some examples of seabed maps derived from the three categories and their applications and uses in the management of Australia's marine jurisdiction.
\end{abstract}

\section{Introduction - information that marine managers need}

The governments of maritime nations commonly employ public servants (ocean managers) whose task it is to implement government polices that aim to limit the impact of human activities on the environment while simultaneously minimizing any added costs to maritime industries. The ocean manager's job is further complicated by the need to account for the cumulative impacts of industry activities (fishing, shipping, port construction, defense, laying of communication cables, oil and gas exploration and development, seabed mining, coastal development) intersecting with a range of legislation enacted to meet different conservation goals. The most common, overarching conservation goals covered by legislation relate to the preservation of biodiversity and the protection of ecosystems. Many books and articles have been published on this topic (for a recent review see Baker and Harris, 2012). 
Perhaps less clear is the role of scientists employed by government in the area of marine management. Their task is to provide a broad-scale context for understanding marine ecosystems and the spatial distribution of species and vulnerable communities having high conservation value. Ocean managers are usually under pressure to provide their governments with options quickly; there is no time for lengthy research programs that may take years to complete. Rather, ocean managers expect scientists to make use of existing data sets to provide succinct, easily-communicated, timely advice.

To address this challenge, government marine scientists have adopted a number of strategies to be able to provide quick, scientifically defensible products to assist the decision-making process. Making use of existing data is a first priority and this requires the establishment and population of centralized databases of key biophysical parameters such as bathymetry, seafloor sediment properties, oceanographic data and satellite remotely-sensed variables (primary production, coastal habitats, etc.). The mantra for government-funded surveying is to "map once use many ways" (Harris and Baker, 2012); hence, bathymetric data collected by hydrographic surveyors for the production of nautical charts are used for creating other products like seabed geomorphic feature maps, seabed rugosity maps, bathymetric grids for hydrodynamic models, habitat maps and others.

In this paper we review three different ways that biophysical and biological data have been used by government marine scientists to support decision-making by ocean managers in Australia. First is the application of seafloor geomorphic feature maps for defining broad, provincial bioregions around the continent of Australia. Second is the derivation of a seascapes classification of the continental shelf based on biophysical data for predicting biodiversity hot-spots to guide in the design of a national representative system of marine protected areas. Finally, predicted coral reef habitat in the Great Barrier Reef (GBR), based on observations of live coral cover together with the distribution of geomorphic banks, illustrates the value of predictive habitat maps in designing and validating GBR marine reserves.

\section{Geomorphic feature maps underpin the definition of bioregions}

Broadly speaking, seafloor geomorphology is the scientific study of the formation, alteration, and configuration of seabed features and their relationship with the underlying geology. The geomorphologic classification of any area of seabed is a fundamental, first-order descriptor containing information about an area's relief, geology, geologic history, and formative processes. Geomorphic classification provides a synthesis of these attributes and information relevant for characterizing habitats. For example, geomorphic features and substrate type are interlinked in as much as some geomorphic features are inherently "rocky" in character (e.g., pinnacles, reefs, and ridges), whereas others are inherently "sediment covered" (e.g., basins, abyssal plains, and sandwaves). Habitat mapping based on geomorphic features has the added advantage that detailed ecological models already exist for many geomorphically defined habitats (Greene et al., 1999; Harris and Baker, 2012). As noted by Roff et al. (2003), marine ecology textbooks are commonly organized into chapters having broad, geomorphically defined habitat types as titles (the ecology of estuaries, coral reefs, temperate rocky reefs, etc.). A good example of the utility of geomorphic features for 
quantifying industrial use in relation to conservation value was provided by Harris et al. (2007) in relation to offshore oil and gas exploration leases in Australia. These workers demonstrated that oil and gas leases coincide with the occurrence of particular types of seafloor geomorphic features (especially shelf valleys, escarpments and submarine canyons) that also have high conservation value.

The ecological implications of geomorphology were fully exploited during the design of Australia's national representative system of marine protected areas (NRSMPA), that aims to protect endemic species found within each of 41 provincial bioregions located around the continent. The provincial bioregions are defined within the Integrated Marine and Coastal Regionalisation of Australia (IMCRA) based on the distribution of demersal fish species and seafloor geomorphology (Commonwealth of Australia, 2006). Specifically, whilst data on fish species endemism was used to define broad geographic bioregions, the actual boundaries between biogeographic provinces are defined based on seabed geomorphology (Heap et al., 2005). The geomorphic features map was also used to assess seafloor heterogeneity, a surrogate for benthic biodiversity, whereby hot-spots of heterogeneous geomorphology were identified as having potentially high biodiversity (and high conservation value; Harris, 2007).

\section{Seascape maps suggest hot spots for biodiversity conservation}

In many situations bathymetric data can be supplemented with other environmental data sets such as oceanographic data (spatial and temporal observations of temperature, salinity, dissolved oxygen, waves and tidal currents, etc.), remotely sensed imagery (showing spatial and temporal patterns of primary production, for example) and seabed substrate data (sediment chemistry and grain size, maps of rock outcrops, seismic data of sediment thickness, etc.). However, ocean managers will generally not be in a position to make use of numerous separate maps. In many cases they will not have the expertise needed to interpret all the different maps, and even if they could, it is simply not practical to try to grasp the ecological meaning of multiple, intersecting data layers, without the use of computers and statistical methods (Roff et al., 2003).

One solution to this problem is to use multivariate statistics to integrate multiple spatial data layers into a single "seascapes" map. Marine scientists at Geoscience Australia have used ER-Mapper's unsupervised ISO class algorithm to simultaneously classify different variables, with equal weighting, to yield a range of statistically different classes (Harris et al., 2008; Heap et al., 2011). The seascapes approach is suggested by niche theory in ecology: every species has a certain range of abiotic (physical and chemical) variables within which it is able to survive and reproduce, a space known as the "fundamental niche" for that species. But most species are unable to fully exploit the entire volume of their fundamental niche because of competition with other species, diseases, and disturbances, all of which reduces their occurrence to a "realized niche." Seascapes are statistically significantly different environments defined from the input data layers, and as such they could individually (or in groups) represent the fundamental niche of particular species. Przeslawski et al. (2011) have discussed the relative strengths and weaknesses of the seascapes approach using existing biological data from the Australian continental shelf. They found that, while seascapes are not consistently useful as surrogates for all communities, they are an 
appropriate surrogate for broad-scale benthic invertebrate community patterns when biological data are limited.

Individual (or selected groups of) seascapes may have their own conservation value in some areas. For example if it is known that shallow, warm-water, high-energy sandy substrate habitat is rare within a bioregion and/or it is utilized by particular threatened species or communities, then that seascape may warrant special consideration in the design of spatial marine planning options. Another way in which seascapes may be useful is in regards to the assessment of seafloor heterogeneity, a surrogate for benthic biodiversity, whereby hot-spots of heterogeneous seascapes may be identified as having potentially high biodiversity (and high conservation value; Harris et al., 2008; Harris and Whiteway, 2009).

\section{Predictive habitat maps define potential niche of species and communities}

In some situations, biological observations are available to supplement and inform the biophysical data sets used to derive seascapes. However, because of the site-specific nature of most biological measurements (taken by towed-cameras or epibenthic sleds along a transect, or at single sites by drop-camera or grab sample) their interpolation to areas of surrounding seafloor was extremely limited prior to the advent of multibeam sonar seabed mapping systems. This new technology produces highresolution ( $\sim 1-5 \mathrm{~m}$ grid resolution) bathymetric data that can be accurately crosscorrelated to sample sites or survey track lines to directly link physical (acoustic) measurements with biological observations. Multibeam sonar technology has revolutionized benthic habitat mapping which is now regularly undertaken by many countries to support ocean management (Harris and Baker, 2012).

Niche theory suggests that by measuring the environmental parameters coinciding with the occurrence of a species and the relative strengths of the different relationships, one should be able to predict the species' fundamental niche. This is the principle behind predictive habitat modeling. Two statistical methods that are most commonly used in predictive habitat modeling among the many that are available (Gusian and Zimmermann, 2000) are decision-trees (De'ath and Fabricius, 2000) and Maxent (Phillips et al. 2004, 2006; Elith et al. 2011). Decision trees are constructed by repeatedly splitting the data, defined by a simple rule based on a single explanatory variable. At each split the data are partitioned into two mutually exclusive groups of optimum homogeneity. The splitting procedure is then applied to each group separately and so on until the desired number of branches is reached (De'ath and Fabricius, 2000). Maxent uses maximum entropy techniques to create models of the relative probability of species/community distribution across a study area. An important distinction between the two methods is that Maxent can use presence-only data, which is commonly the case in biological surveying (Elith et al., 2011).

As an example of predictive habitat modelling we here examine the distribution of coral communities in the Great Barrier Reef. Most near sea surface (NSS) coral reefs may be seen in remotely sensed imagery; other reefs are submerged below the surface and are invisible to satellites. Ocean managers need to know about the distribution of both types to ensure they are protected as required by government legislation. The problem is, we do not have a map of the submerged coral communities. 
A solution is to use the geomorphology of the GBR to estimate the distribution of submerged coral communities (Harris et al., in prep.). Since coral reefs grow preferentially upon geomorphic banks, a map of banks was created using a new $100 \mathrm{~m}$ resolution bathymetric grid. Analysis of this map shows that only about $37 \%$ of available seabed on submerged banks is capped by NSS coral reefs $\left(16,110 \mathrm{~km}^{2}\right)$; the other $63 \%$ of bank area $\left(25,599 \mathrm{~km}^{2}\right)$ is submerged at a mean depth of around $27 \mathrm{~m}$ and represents potential deep reef habitat. In order to estimate potential coral cover of the submerged banks, a high-resolution multibeam sonar data set was used. Areas likely to support deep-water coral communities were identified using coral occurrence records derived from optical images taken by autonomous underwater vehicle, and geophysical data on depth, slope, aspect, rugosity, sidescan acoustic backscatter (a surrogate for substratum roughness and type), and geomorphic zone (slope, crest, flat or depression) gridded at $5 \times 5 \mathrm{~m}$ pixel resolution.

Out of $25,599 \mathrm{~km}^{2}$ of submerged bank area, predictive habitat modelling indicates that more than half (around 14,000 $\mathrm{km}^{2}$ ) is potentially occupied by coral communities. These results indicate that the total area of coral cover in the GBR is much greater (perhaps twice as large) as has been assumed based on maps of NSS reefs derived from satellite imagery alone (Harris et al., in prep.).

\section{Discussion and final remarks}

The spatial representations of the environment discussed above (geomorphology, seascapes and predictive habitat models) may be thought of as illustrating a progression for the utilization of environmental information, from data-poor to datarich situations. Such a data-poor to data-rich gradient occurs as we move from local to global spatial scales and also from developing to industrialised countries. The scale dependence of data is obvious; high resolution data for almost all variables is lacking at a global scale. Initiatives such as the ETOPO-1 bathymetry, NOAA's Ocean Atlas and the Census of Marine Life, have provided global scale data sets but often the resolution is very low and broad extrapolations are needed to produce a map, with attendant errors.

Even so, it is interesting to note that many global data sets are available having a resolution of from 2 to $10 \mathrm{~km}$, which has allowed a seascapes type analysis to be carried out at a global scale (Harris and Whiteway, 2009). Such a resolution may be useful for management of national exclusive economic zones (i.e. 200 mile limits), and also for decision-making at the international level for the high seas and areas beyond national jurisdiction. An area of future research is to integrate the available global biophysical data with the 30 million biological observations collated by the Census of Marine Life for predictive habitat modeling at a global scale. Such a global model would have broad applications for decision-making at national and international levels.

\section{References}

Baker, E. K., and Harris, P. T. 2012. Habitat Mapping and Marine Management. In Seafloor Geomorphology as Benthic Habitat: GeoHab Atlas of seafloor geomorphic features and benthic habitats. Ed. by P. T. Harris, and E. K. Baker. Elsevier, Amsterdam, p 23-38. 
Commonwealth of Australia, 2006. A Guide to the Integrated Marine and Coastal Regionalisation of Australia Version 4.0.16 pp. http://www.environment.gov.au/coasts/mbp/publications/imcra/pubs/imcra4.pdf

De'ath, G., and Fabricius, K. E. 2000. Classification and regression trees; a powerful yet simple technique for the analysis of complex ecological data. Ecology, 8: 31783192.

Elith, J., Phillips, S.J., Hastie, T., Dudik, M., Chee, Y.E., Yates, C.J., 2011. A statistical explanation of MaxEnt for ecologists. Diversity and Distributions 17, 43-57.

Greene, H. G., Yoklavich, M. M., Starr, R. M., O'Connell, V. M., Wakefield, W. W., Sullivan, D. E., McRea, J. E., et al. 1999. A classification scheme for deep seafloor habitats. Ocenaologica Acta, 22: 663-678.

Harris, P. T. 2007. Applications of geophysical information to the design of a representative system of marine protected areas in southeastern Australia. In Mapping the Seafloor for Habitat Characterisation, pp. 449-468. Ed. by B. J. Todd, and G. Greene. Geological Association of Canada Special Paper 47, St Johns, Newfoundland, Canada.

Harris, P. T., and Baker, E. K. (Editors) 2012. Seafloor Geomorphology as Benthic Habitat: GeoHab Atlas of seafloor geomorphic features and benthic habitats. Elsevier, Amsterdam, 947 pp.

Harris, P. T., Bridge, T. C. L., Beaman, R., Webster, J., Nichol, S., and Brooke, B. (in prep.). Submerged banks in the Great Barrier Reef, Australia, greatly increase available coral reef habitat. ICES Journal of Marine Science.

Harris, P. T., Heap, A., Post, A. L., Whiteway, T., Potter, A., and Bradshaw, M. 2007. Marine zone management and the EPBC Act: How environmental marine geological information provides certainty for petroleum exploration. APPEA Journal, 46: 327-343.

Harris, P. T., Heap, A. D., Whiteway, T., and Post, A. L. 2008. Application of biophysical information to support Australia's representative marine protected area program. Ocean and Coastal Management, 51: 701-711.

Heap, A. D., Anderson, T. J., Falkner, I., Przeslawski, R., Whiteway, T., and Harris, P. T. 2011. Seascapes for the Australian margin and adjacent seabed. ICES Document 2011/06. 92 pp.

Heap, A. D., Harris, P. T., Hinde, A., and Woods, M. 2005. Draft Benthic Bioregionalisation of Australia's Exclusive Economic Zone - Geoscience Australia Report to the National Oceans Office. 140 pp.

Phillips, S.J., Dudik, M., Schapire, R.E., 2004. A maximum entropy approach to species distribution modeling. In: Proceedings of the $21^{\text {st }}$ International Conference on Machine Learning, Banff, Canada, 8 pp.

Phillips, S.J., Anderson, R,P,, Schapire, R.E., 2006. Maximum entropy modeling of species geographic distributions. Ecological Modelling 190: 231-259

Przeslawski, R., Currie, D. R., Sorokin, S. J., Ward, T. M., Althaus, F., and Williams, A. 2011. Utility of a spatial habitat classification system as a surrogate of marine benthic community structure for the Australian margin. ICES Journal of Marine Science: Journal du Conseil, 68: 1954-1962.

Roff, J. C., Taylor, M. E., and Laughren, J. 2003. Geophysical approaches to the classification, delineation and monitoring of marine habitats and their communities. Aquatic Conservation: Marine and Freshwater Ecosystems, 13: 77-90. 